SUPPORTING INFORMATION

\title{
A Resonance Raman marker band characterizes the slow and fast form of cytochrome c oxidase
}

Fabian Kruse ${ }^{\mathrm{a}}$, Anh Duc Nguyen ${ }^{\mathrm{b}}$, Jovan Dragelj ${ }^{\mathrm{b}}$, Joachim Heberle ${ }^{\mathrm{c}}$, Peter Hildebrandt ${ }^{\mathrm{b}}$, Maria Andrea Mroginski ${ }^{b}$, Inez M. Weidinger ${ }^{\mathrm{a}}$

${ }^{a}$ Department of Chemistry and Food Chemistry, Technische Universität Dresden, 01069 Dresden, Germany

${ }^{b}$ Department of Chemistry, Technische Universität Berlin, Strasse des 17. Juni 135, 10623 Berlin

${ }^{c}$ Freie Universität Berlin, Department of Physics, Experimental Molecular Biophysics, Arnimallee 14, 14195 Berlin, Germany

\section{Content}

Figure S1: Excerpt of the UV vis spectrum of CcO

Figure S2: Potential dependent SERR spectra at $413 \mathrm{~nm}$ excitation

Figure S3: Averaged and high quality spectra of $\mathrm{CcO}$ in slow and fast form preparation at 647 nm excitation.

Figure S4. Optimized structural models of BNC with dioxo moiety

Table S1: Calculated frequencies of oxygen vibrations 


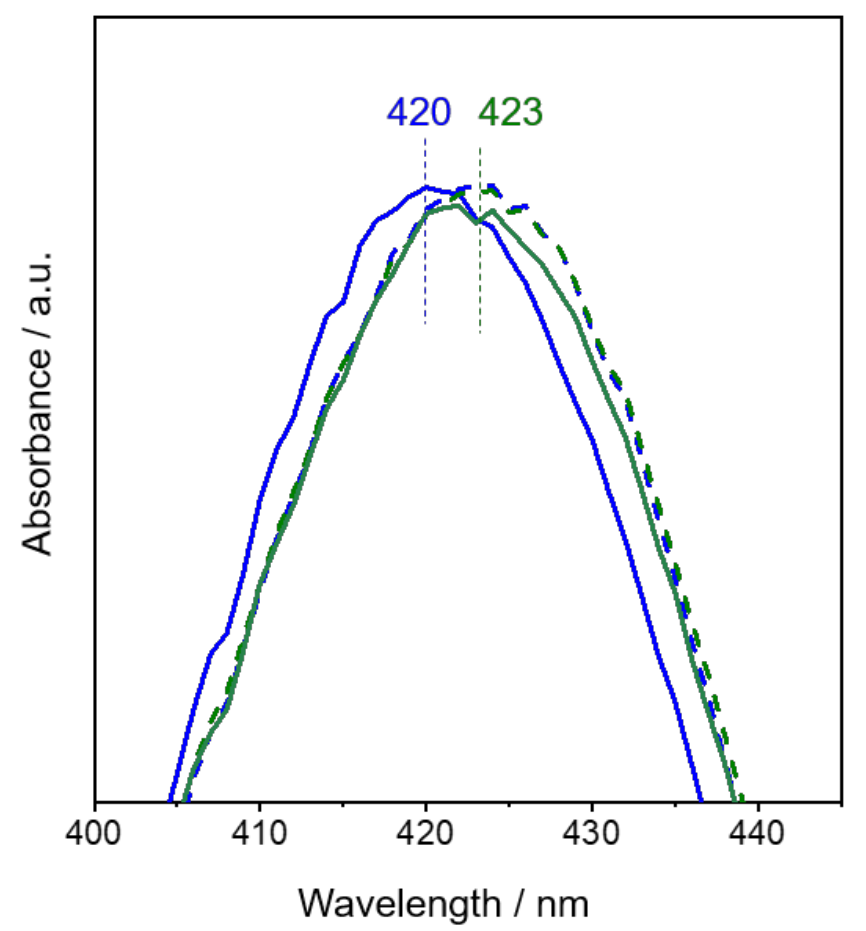

Figure S1: Excerpt of the UV vis spectrum of $\mathrm{CcO}$ in $0.2 \mu \mathrm{M}$ (blue lines) and $0.5 \mu \mathrm{M}$ (green lines) featuring the Soret band maximum. The dashed spectra were recorded directly after a change of $\mathrm{pH}$ from 8 to 6 . The solid line spectra were recorded after an exposure time of 12 h. Only for the $0.2 \mu \mathrm{M}$ concentrated batch a shift of the Soret-band maximum from 423 to 420 , indicating slow form formation, is observed.

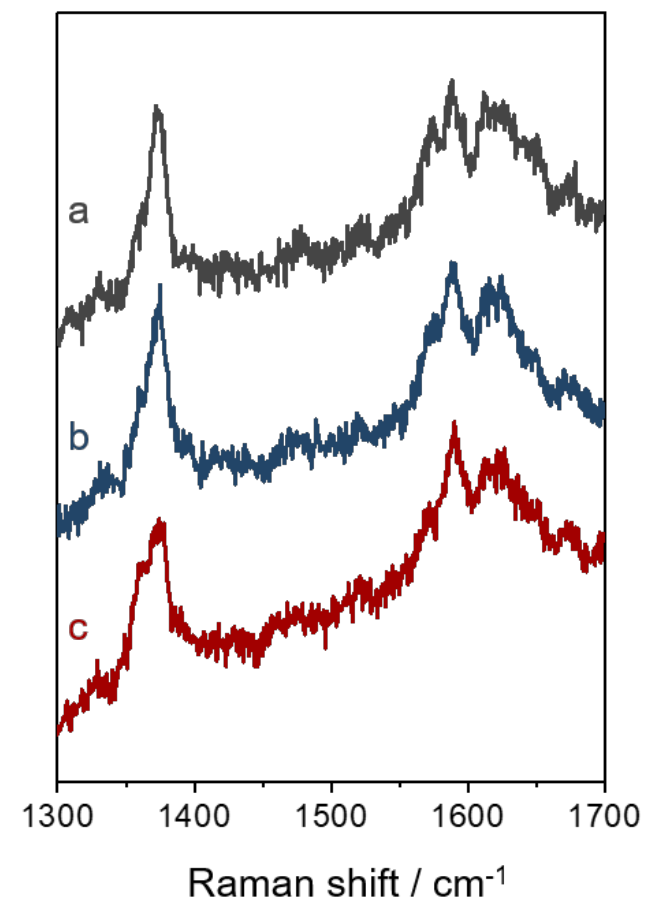

Figure S2: SERR spectra of CcO using $413 \mathrm{~nm}$ laser excitation under open circuit potential (a), at $+60 \mathrm{mV}$ (b) and $-400 \mathrm{mV}$ (c) vs. Ag|AgCl. At $-400 \mathrm{mV}$ partial reduction of the enzyme is detectable. No change in SERR intensity is, however, observed in this potential range. 


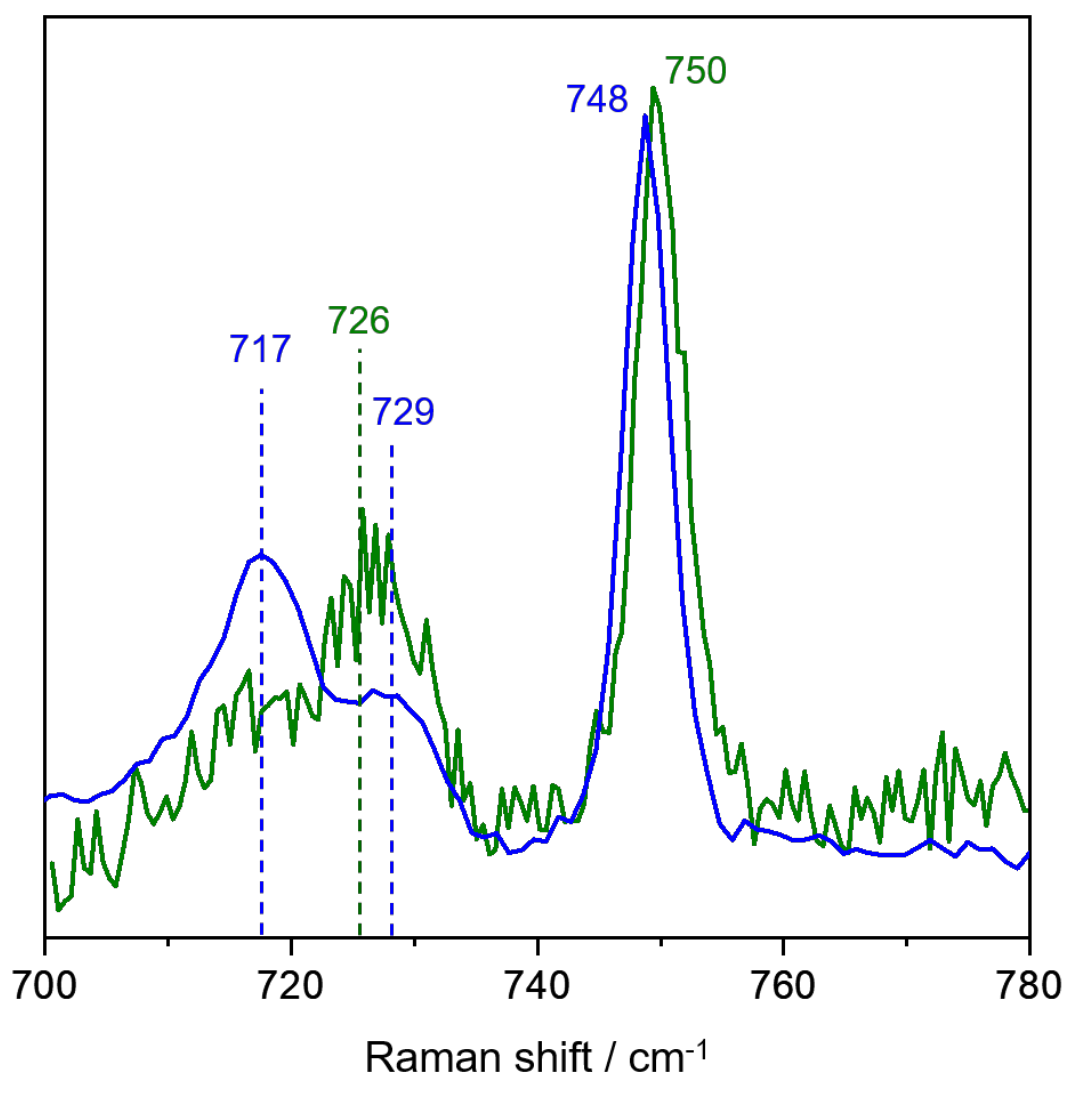

Figure S3: SERR spectra of $\mathrm{CcO}$ using $647 \mathrm{~nm}$ laser excitation prepared under conditions that yield dominantly the fast form (green line, $\mathrm{pH} 8, \mathrm{c}=0.5 \mu \mathrm{M}$ ) or the slow form (blue line, $\mathrm{pH} 6, \mathrm{c}=0.2 \mu \mathrm{M}, \mathrm{t}>12 \mathrm{~h}$ ). The green spectrum is an average over 6 measurements, whereas the blue spectrum corresponds to a high quality single spectrum. A clear shift from the marker band maximum from $748 \mathrm{~cm}^{-1}$ to $750 \mathrm{~cm}^{-1}$ is visible. The broad vibrational bands with maximum at 717,726 and $729 \mathrm{~cm}^{-1}$ correspond to in-plane and out-of plane heme skeletal modes. 


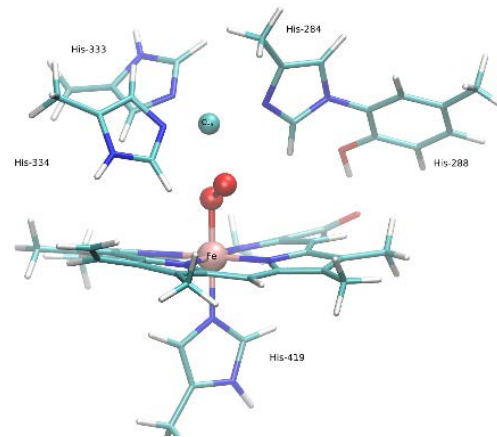

a) $\mathrm{Cu}-\mathrm{O}-\mathrm{O}-\mathrm{Fe} \mathrm{Tyr}-\mathrm{OH}$

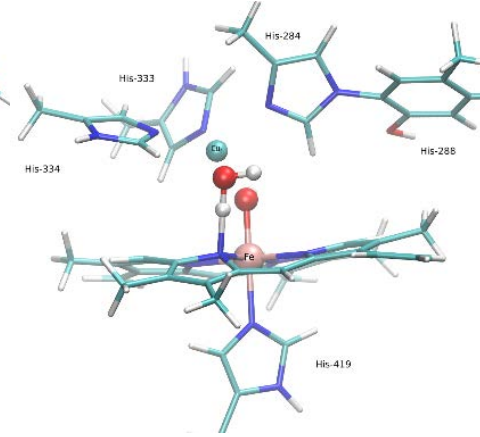

b) $\mathrm{Cu}-\mathrm{H}_{2} \mathrm{O}-\mathrm{OH}-\mathrm{Fe} \mathrm{Tyr}-\mathrm{OH}$

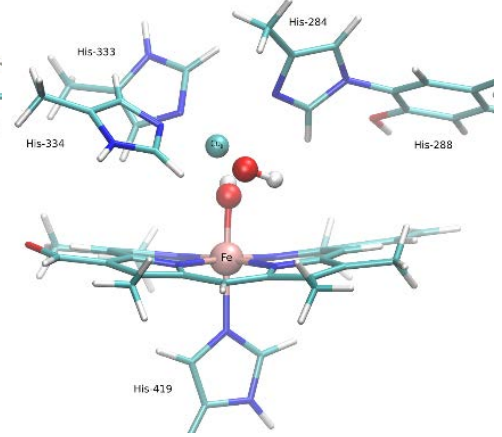

c) $\mathrm{Cu}-\mathrm{OH}-\mathrm{OH}-\mathrm{Fe} \mathrm{Tyr}-\mathrm{OH}$

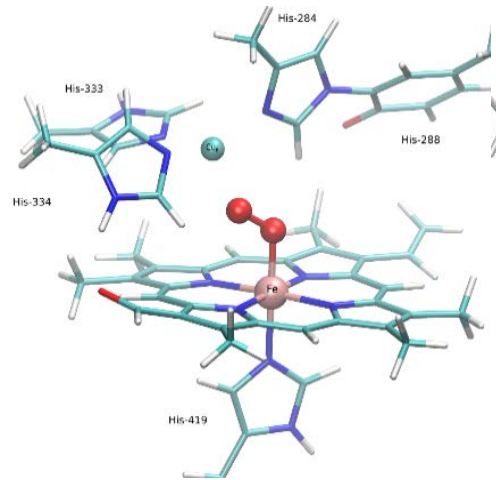

d) Cu-O-O-Fe Tyr-O

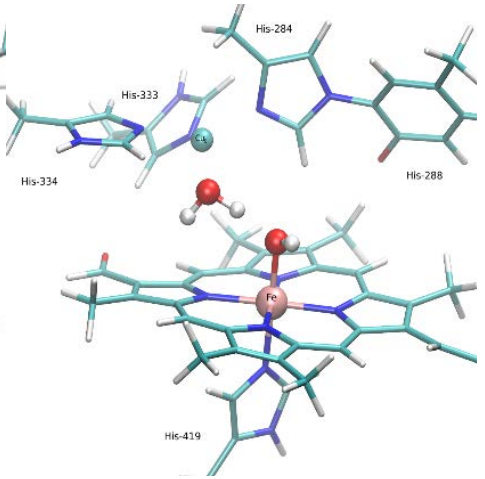

e) $\mathrm{Cu}-\mathrm{H}_{2} \mathrm{O}-\mathrm{OH}-\mathrm{Fe}$ Tyr-O

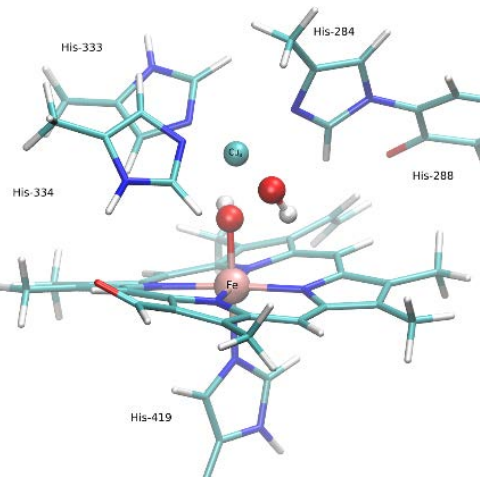

f) $\mathrm{Cu}-\mathrm{H}_{2} \mathrm{O}-\mathrm{OH}-\mathrm{Fe}$ Tyr-O

Figure S4: Optimized structural models of BNC with dioxo moiety.

Table S1: Calculated frequencies of oxygen vibrations

\begin{tabular}{|c|c|c|c|c|c|}
\hline \multicolumn{2}{|c|}{$\begin{array}{c}\text { Cu-O-O-Fe } \\
\text { (Tyr-288-OH) }\end{array}$} & \multicolumn{2}{c|}{$\begin{array}{c}\text { Cu-O-O-Fe } \\
\text { (Tyr-288-O) }\end{array}$} & \multicolumn{2}{c|}{ (Tyr-288-O) } \\
\hline$v\left(\mathbf{c m}^{-1}\right)$ & PED & $v\left(\mathbf{c m}^{-1}\right)$ & PED OH-Fe & $v\left(\mathbf{c m}^{-1}\right)$ & PED \\
\hline 471 & $69 \%$ Fe-O 2 str. & 448 & $75 \%{\mathrm{Fe}-\mathrm{O}_{2} \text { str. }}^{-1}$ & 556 & $59 \%$ Fe-OH str. \\
\hline 1000 & $30 \%$ O-O str. & 1041 & $92 \%$ O-O str. & & \\
1013 & $43 \%$ O-O str. & & & & \\
\hline
\end{tabular}

